\title{
Improving Fault Tolerance of Internal Combustion Gas Engine for Internal Faults Air-Fuel Ratio Control
}

\author{
M.Shunmathi ${ }^{1}$, KA.Arirajan ${ }^{2}$ \\ Department of Mechanical Engineering, Thiagarajar College of Engineering, Madurai
}

\begin{abstract}
*Corresponding Author: M.Shunmathi, Department of Mechanical Engineering, Thiagarajar College of Engineering, Madurai
\end{abstract}

\begin{abstract}
The dependability of a cycle machine can be altogether upgraded by presenting a deficiency lenient control framework in it. Equipment excess is a significant view point to upgrade adaptation to internal failure capacity and is concentrated in this paper. An epic adjusted triple secluded excess (ATMR) approach is proposed for the sensors to maintain a strategic distance from a closure on account of synchronous shortcomings in more than one sensor, and double repetition is proposed for the actuators to dodge a solitary purpose of disappointment because of the single actuator issue. The exhibition of the control framework is confirmed by reenactment in MATLAB Simulink software. The proposed ATMR satisfies the hole in regular TMR by keeping up soundness even on account of synchronous issues in two channels. Cost and advantage examination (TCBA) is completed to decide the monetary plausibility of the execution of the proposed framework.
\end{abstract}

\section{INTRODUCTION}

A deficiency is characterized as the deviation of a framework boundary from its typical reach. Shortcomings in the framework segments, for example, sensors and actuators can cause disappointment of the total framework. An issue open minded control framework (FTCS) can proceed to work and keep up dependability even in the functions of issues in the sensors and actuators. There is extraordinary exploration being conveyed in the FTCS area [1]-[3]. Flaws in a framework cause stumbling of the machines and consequently, creation misfortune supporting the inclusion of the FTCS in the creation plants for expanding the unwavering quality of machines for expanded benefits. A FTC is principally ordered into two sorts: dynamic and passive. In the dynamic FTCS (AFTCS), a devoted unit named as deficiency recognition and confinement (FDI) is utilized to recognize and separate the broken segments. After shortcoming separation, regulator reconfiguration is performed to adjust to the new conditions. Nonetheless, the AFTCS has a very mind boggling structure and is delayed because of unnecessary calculations. In the latent FTCS (PFTCS), no FDI is utilized rather blames are considered at the plan stage. Time reaction of the PFTCS is quick when contrasted with the AFTCS yet its activity is restricted to the flaws characterized at the plan stage [4]-[6]. Excess is one of the main parts of FTCS plan in which two segments play out a similar activity in equal. If there should be an occurrence of a shortcoming in the essential segment, other repetitive or reinforcement segment come into activity and keep up framework coherence. Repetition can be arranged into equipment and explanatory. In the equipment excess, additional equipment is added to the framework. In the expository excess, no extra equipment is added rather programming model is made to create a virtual yield of the real estimation. This virtual yield is utilized in the control framework arise an occurrence of an issue. The logical excess can spare cost and decrease the size and weight of the framework yet is firmly subject to the exactness of the product model [7], [8]. Double repetition and Three Modular Redundancy (TMR) are the most generally utilized equipment excess methods. In double repetition, ordinary activity is done with two comparable segments introduced in equal one is the essential segment. In the event of a shortcoming in the Essential segment, optional part comes into activity and broken one is separated which may then be supplanted. In regular TMR, three indistinguishable channels play out a comparable capacity of creating yield from a similar contribution to resemble autonomously with each other. A citizen at that point performs casting a 
ballot among the yields to decide the single yield from the framework. In the event that one channel gets broken subsequently giving whimsical yield, citizen settles on the rest two solid channels. This repetition plot is additionally called as 2 out of 3 rational (2003) as appeared in Fig. 1 [7], [10], [11].Single purpose of disappointment is a significant angle in solid control frameworks which is a condition where flaw in a solitary segment of a framework can cause complete framework disappointment. Equipment excess kills a solitary purpose of disappointment and improves the accessibility of the framework [9]. The traditional TMR has been generally utilized in the supportive of wellbeing applications. In [12] TMR conspire has been proposed for four sensors in the chip engineering of the VLSI framework. In [13] TMR is executed for advanced control frameworks. In [14] a TMR elector frame work is executed at Nano electronic field level for CMOS circuits. In [15] TMR has been actualized for the working frameworks. Nonetheless, there is a significant disadvantage in the traditional TMR that the framework can't deliver yield in the event of a synchronous deficiency in two channels [7]. In such a case, a caution conspire is normally executed to make the administrator aware of check for the flawed divert should an issue in a channel emerge and get it fixed or supplanted at the earliest opportunity. Substitution or fix of the parts can be performed online without intruding on the cycle. The ordinary TMR has a significant defect that in the event of more than one channels disappointment, it stops to create an out-put causing framework disappointment. In this manner, a serious form of TMR is vital which can proceed with activity even if there should be an occurrence of disappointment of two channels. This examination hole is satisfied in this exploration work by proposing another ATMR method. Determine the value of $R=0.7, R_{T M R}=$ 0.925.The engineering of the proposed MTMR is like the conventional TMR, as appeared in Fig. 1, however with some extra control highlights. Since the traditional TMR can't give yield if there should be an occurrence of a flaw in two channels, the ATMR will have the option to furnish yield in this condition with the main single sound channel. Accordingly, proposed ATMR is a serious version and more dependable than the traditional TMR. This has been executed in this paper for the sensors in the AFR control framework and its presentation has been confirmed through reenactment in MATLAB by presenting issues in the sensors individually. In this paper, our commitment is the use of cutting edge FTC equipment excess strategies for unwavering quality improvement of the motor AFR control framework. We have proposed a serious form of existing generally utilized strategy i.e., TMR by satisfying its hole. The oddity of the work is proposing new equipment excess methodology ATMR for sensors in mix with double repetition in the actuator. The proposed approach is exceptionally dependable and not found in the writing so far up to our best information for the IC motor AFR control and some other comparative cycle application. Proposed equipment repetition way to deal with the modified AFR control is very huge for additional examination and car industry for assembling exceptionally solid gas motors. This control framework can likewise be presented in current establishments in the business just as new impending models of gas motors to profit more noteworthy dependability benefits. Since it includes expenses of adding additional equipment, ICBA is performed to decide the budgetary achievability of additional expense.

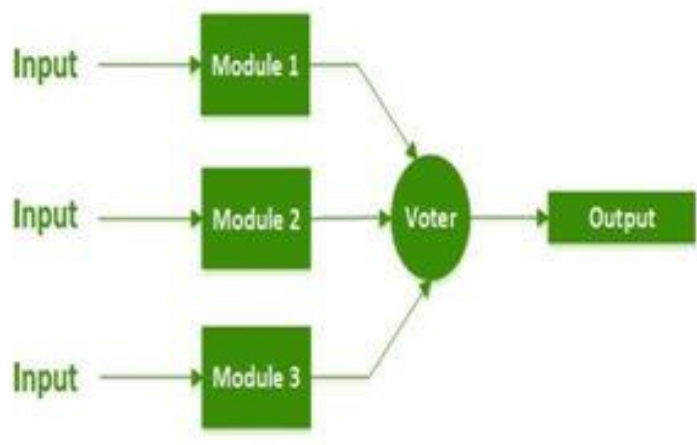

Figure1. Traditional Diagram TMR

\section{RESEARCH METHODOLOGY}

The Fault lenient fuel control model of the IC gas motor accessible in the Simulink is utilized in this investigation for implementation of cutting edge equipment excess plans. The control framework in the first model is intended to endure blames in the sensors without considering actuator shortcomings. 
The point by point practically of the control framework both in typical and flawed sensor conditions as of now clarified in [26]. The constraint of this model is that motor can endure shortcomings in just a single sensor at a time and gets closed down if there should be an occurrence of concurrent disappointment of more than one sensor. Fuel actuator is additionally absent in the model and is presented in our new model according to reasonable air-fuel model of the motor to give directed fuel flexibly. A flaw is presented in this actuator and its impact on the AFR is noticed. Single actuator disappointment will cause a shut down of the motor cutting the fuel gracefully, consequently, the excess is proposed for it to maintain a strategic distance from a solitary purpose of disappointment. Nonetheless, no time delay is expected in the exchanging of the actuators. Just full sensor and actuator deficiency types are considered in this investigation. Fractional sensor and actuator issues are not thought of. A serious form of FTC procedure, ATMR, is implemented for the sensors for improved dependability and to keep away from shut down because of concurrent issues in more than one sensor. As examined in segment 1 , the ATMR can give a yield a solitary direct in the event of concurrent issues in two channels. A money related instrument cost and advantage examination (ICBA) is utilized to decide the attainability for the expansion of the equipment repetition in the model.

\section{Air Fuel RATio}

An inner ignition gas motor is a broadly utilized hardware as the main player in the process business for power age and gas pressure frameworks. It changes substance energy of the fuel over to mechanical rotational energy. This rotational energy is additionally applied to the alternator to create power or a gas/air blower for the compression measure [16]. In a four-stroke IC motor, fuel is joined with air to deliver an air-fuel combination and is singed in the chambers to create high-pressure gases causing mechanical development of the camshaft and driving rod [17]. Air-fuel proportion (AFR) or Lambda $(\lambda)$ improvement is vital in the exhibition and energy proficiency of the gas motors.

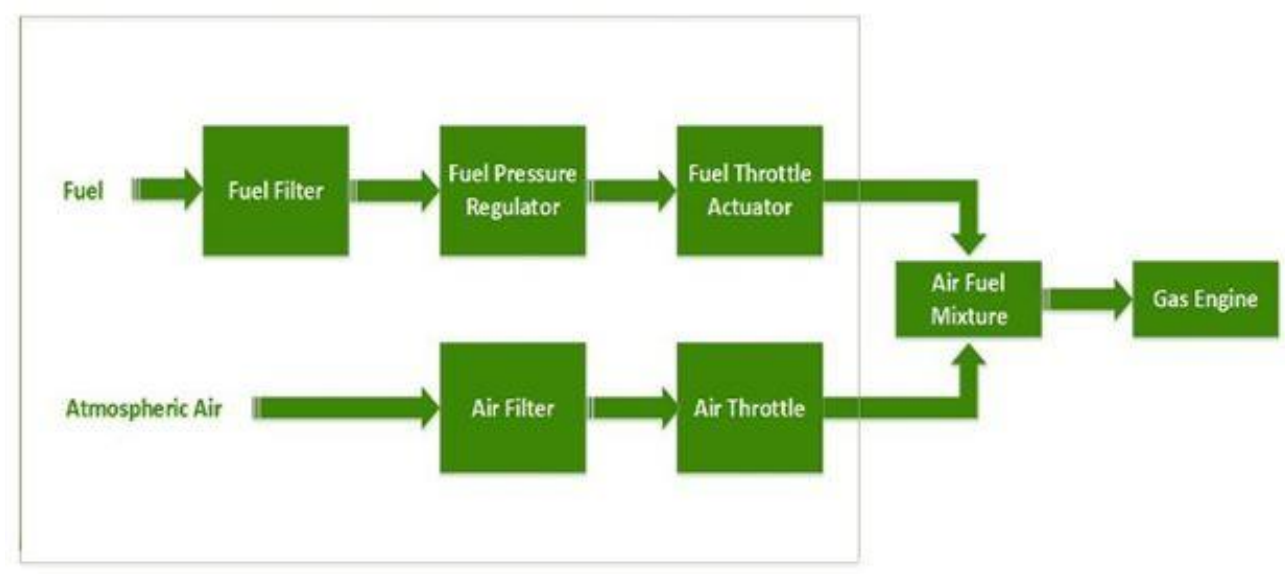

Figure2. Air fuel system

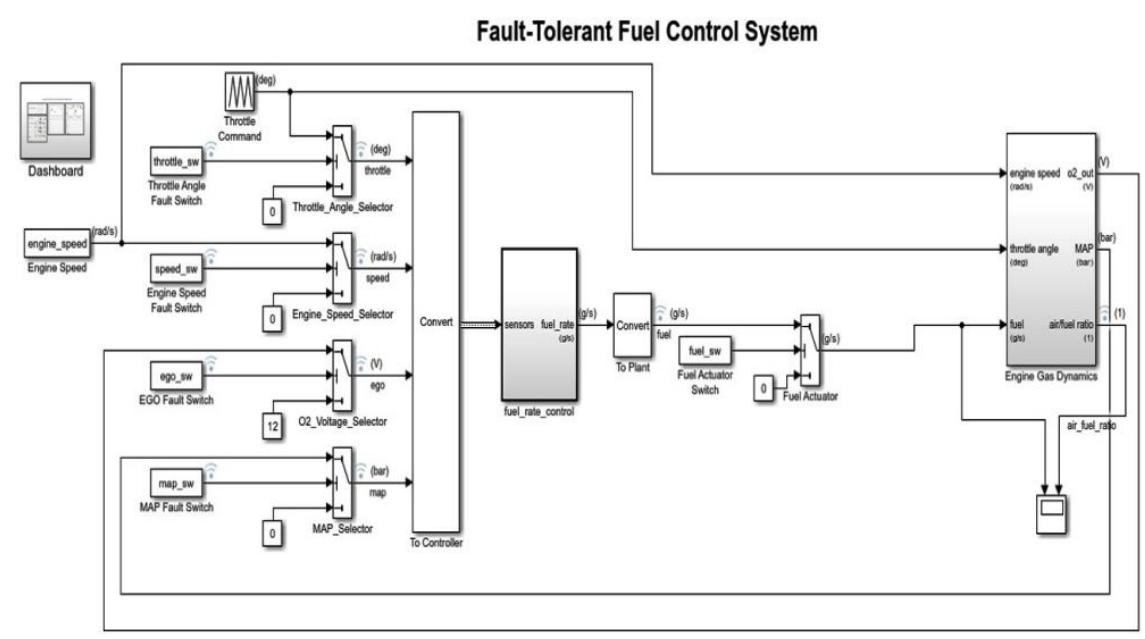

Figure3. Consolidation of the fuel actuator in the fuel gracefully line 
The combination with the advanced air-fuel proportion is likewise called as a stoichiometric air-fuel blend. The stoichiometric blend frames the ideal proportion of air to fuel that consumes all fuel with no overabundance air. For gas fuel, the stoichiometric air-fuel blend is about 14.6:1. On the off chance that the proportion is more prominent than 14.6, there is abundance air than the fuel and the combination would be named as a lean blend. In the event that the proportion is under 14.6, there are more fuel substance and the combination is named as a rich blend. Both lean and rich blends don't offer ideal burning and cause extra of unburnt carbon particles and carbon monoxide which cause ecological and medical issues. Besides, these additionally decline the motor proficiency and cause more fuel cost. Along these lines, in an AFR fuel control framework, the essential goal is to accomplish this proportion [18], [19].Block outline of an air-fuel arrangement of a useful sparkle start (SI) IC gas motor is appeared in Fig. 2. Fuel is first sifted to eliminate unfamiliar particles and afterward controlled by a weight controller at explicit weight according to the plan prerequisite of the motor. It is then gone through a choke valve for the AFR changes. Barometrical air is sifted and gone through the air choke valve for wind current changes. Both air and fuel are then blended and shipped off motor chambers for burning [20].Deficiencies in the sensors and actuators of the AFR control framework cause motor closure, in this way, causing creation misfortune. Hence, a profoundly dependable AFR control framework is significant for IC motors. Different methods have been utilized for the plan of the AFR control framework. The AFR control by sliding mode control strategy is accounted for in [21] in which MIMO regulator is intended for different stream unsettling influences in the motor. A nonlinear methodology for AFR control Takagi-Sugeno's model is accounted for in [22] that considers the variable time delay. In [23] a Smooth Super-Twisting Algorithm (SSTA) is accounted for the AFR control utilizing the Mean Value Engine Model (MVEM) that has decreased jabbering impact. In [24] Fuzzy Sliding-mode Strategy is accounted for which is sans model without requiring any framework attributes and has unrivaled guideline execution. In [25] a PI-like fluffy information based regulator is accounted for that makes them tune ability and is exceptionally powerful. In [26] Fault-Tolerant fuel control framework accessible in Mat-lab for IC gas motor model is accounted for with a total depiction of flaw recognition and detachment, AFR control and explanatory excess. In this model, the scientific redundancy has been utilized for sensors utilizing the look-into tables that give assessed estimations of the sensors if there should be an occurrence of a shortcoming in the sensors. This model is utilized in this exploration concentrate for dependability improvement of the AFR control framework. In this model, the accompanying four sensors assume a significant part noticeable all around fuel proportion control arrangement of the gas motor [26].

- Throttle Position Sensor: gives input of the air choke actual situation to the motor regulator.

- Engine Speed Sensor: gives input of the motor speed in RPM to the regulator.

- Exhaust Gas Oxygen (EGO) Sensor: gives the oxy-gen content in the fumes gas of the motor to change the fuel flexibly.

- Manifold Air Pressure (MAP) Sensor: gives pull weight of the wind current at consumption complex of the motor. The sensor esteem is utilized to compute air thickness and air mass stream rate.

In this model, a vital input proportion control is implemented to keep up the AFR to 14.6 with a diminished consistent state blunder in ordinary activity. Deficiency location and disengagement are performed by the motor control unit worked with the state stream graph in which look-into tables are utilized to give assessed estimations of the broken sensors for the analytical excess [25].

In the event of a shortcoming in any each sensor in turn, the assessed estimation of that sensor is given by the look-into table to maintain a strategic distance from motor shut down yet AFR gets corrupted to 11.7. The model experiences some significant lacks. Above all else, the current model just presents FTC for sensors without considering actuator shortcomings. We have proposed a profoundly dependable answer for both sensor and actuator shortcomings. Besides, fuel actuator isn't consolidated in the fuel flexibly line however it is a significant part in the commonsense gas motors in giving controlled fuel gas gracefully to the motor according to stack interest and AFR control. We have consolidated this actuator in our model and adaptation to internal failure is accomplished for it. Thirdly, explanatory excess of motor control is planned with the end goal that it can endure just each 
flaw in turn in any one sensor. Concurrent issues in any two sensors cause motor closure which is an exceptionally unwanted element in the current model. We have proposed equipment repetition to forestall motor closure in the event of synchronous shortcomings in any two sensors all at once. Our supposition in this model is the zero exchanging time for the repetitive sensors and actuators. Basically, a period delay happens during the changeover of the parts. The restrictions of the examination are as per the following: 1) Partial deficiencies in the sensors and actuators are not considered in the model; sensors and actuators are completely useful or completely flawed.2) A serious vigorous AFR regulator with fuel actuator isn't executed in this examination study. Or maybe existing vital input control of the first MATLAB model is utilized for AFR control. 3) Only reproduction and cost point of view are considered in this examination for adding additional equipment. Impacts on the size increment of the motor are not considered in this investigation. 4) Fault identification and seclusion (FDI) measure dependent on the state stream rationale outline in the first MATLAB model is utilized in our new model with the primary spotlight on the serious equipment repetition recreation and cost investigation.

\section{Simulation Of Sensor Faults}

Deficiency in every one of the four sensors is mimicked individually considering each issue in turn and the comparing impact on AFR is appeared in Fig. 10 for every sensor. The framework keeps up steadiness with one sensor issue because of as of now implemented expository repetition plot, clarified in [26] however AFR gets corrupted to 10.3 from 12.7 in defective conditions according to effortless debasement. The framework is closed down if there should be an occurrence of synchronous blames in the event of more than one sensor. The ATMR conspire is executed for the sensors in the model and is appeared in Fig. 11.The dashboard of the model is refreshed to reproduce issues in the individual sensors in the ATMR gatherings as appeared in Fig. 12. The interior engineering of the ATMR block is appeared in Fig. 13 which comprises of the control block, port selector block, and the elector block. The control square of the ATMR is appeared in Fig. 14. This square plays out the capacity of the ordinary TMR to create a yield from each of the three sound sensors and two solid sensors if there should a rise an occurrence of a deficiency in one sensor. Four AND entryways are introduced, initial one is for all operating sensors and the other three are for two operating sensors in the event of one flawed sensor. Rationale diagram of the control block is appeared in table 1. Port selector square of the ATMR. It creates the port number of the citizen relying on the accessible sensor data to deliver output from the ATMR block. The control outline of the port selector block is appeared in Table 2. An extra component of the ATMR is accomplished by this square in which a solitary sensor likewise furnishes a yield with other two bombed sensors though in ordinary TMR yield isn't produced if there should be an occurrence of a flaw in two sensors. Execution of the ATMR for flaw in one sensor of a solitary ATMR gathering is appeared in Fig. 16. It shows that the flaw in one sensor doesn't influence the framework execution. Execution of the ATMR for concurrent shortcomings in two sensors of a similar square is appeared which shows that issue in two sensors don't influence framework execution as the framework returns to the last solid sensor. This property isn't accessible in regular TMR. The proposed profoundly repetitive framework can endure simultaneous shortcomings in sensors and actuators aside from the most pessimistic scenario of disappointment of any two complete ATMR sensors or redundant fuel or air choke actuators which will prompt motor closure.

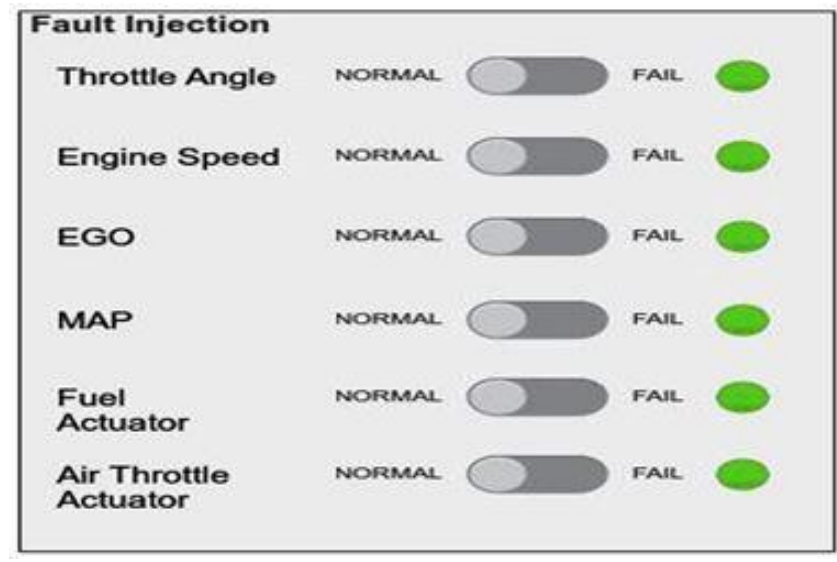

Figure4. Fault injection 
Improving Fault Tolerance of Internal Combustion Gas Engine for Internal Faults Air-Fuel Ratio Control
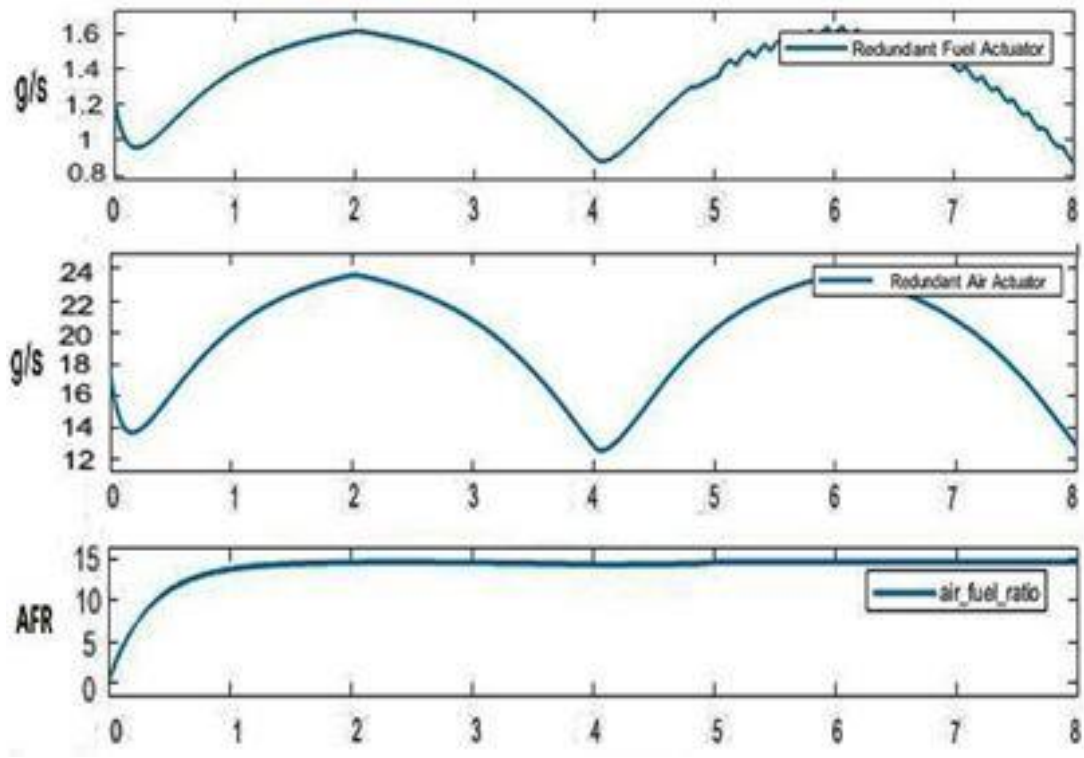

Figure5. AFR conditions
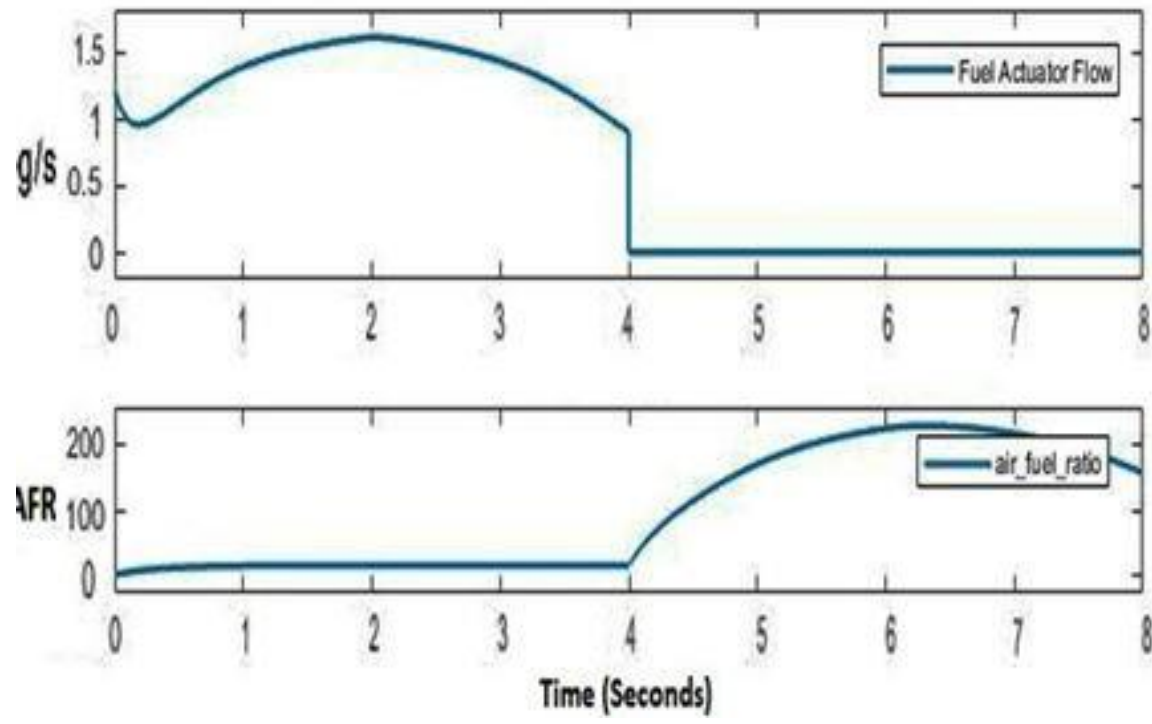

Figure6. Impact of the fuel actuator failure on AFR

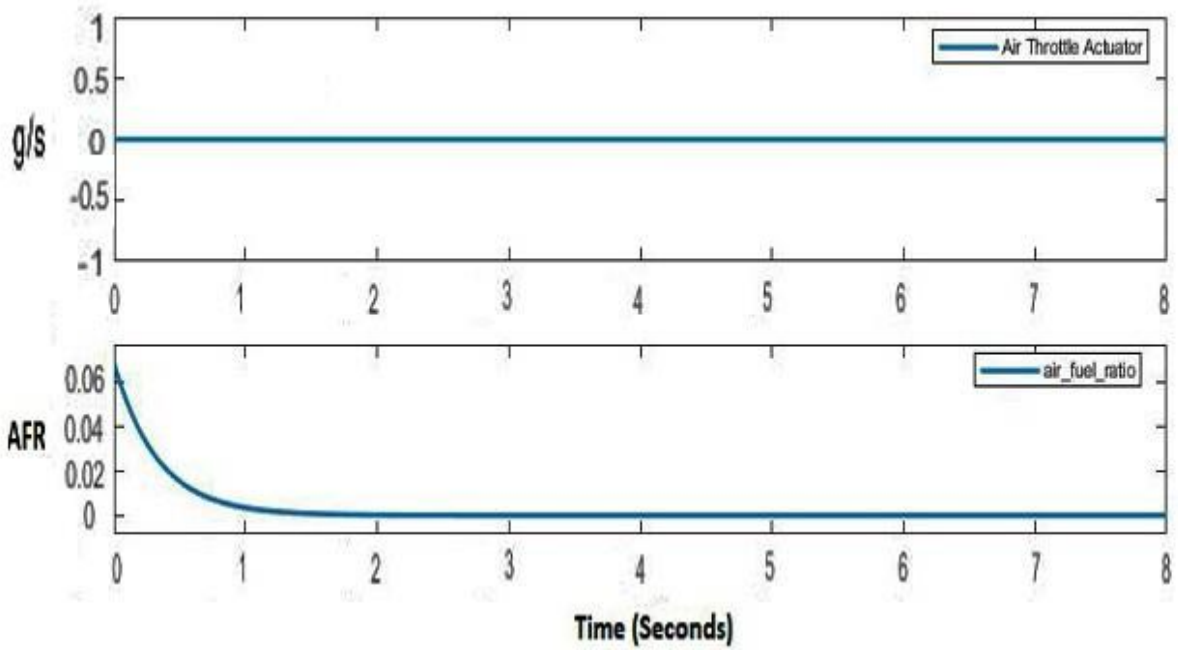

Figure7. Impact of the air actuator failure on AFR 


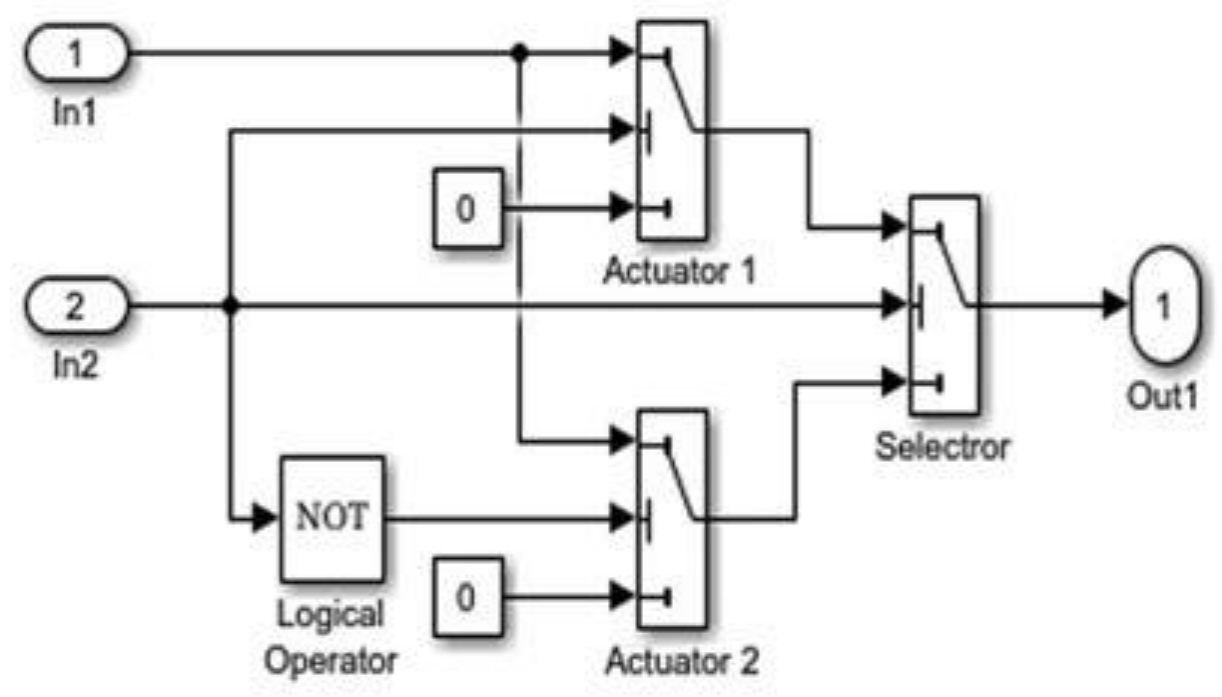

Figure8. Excess actuator connection

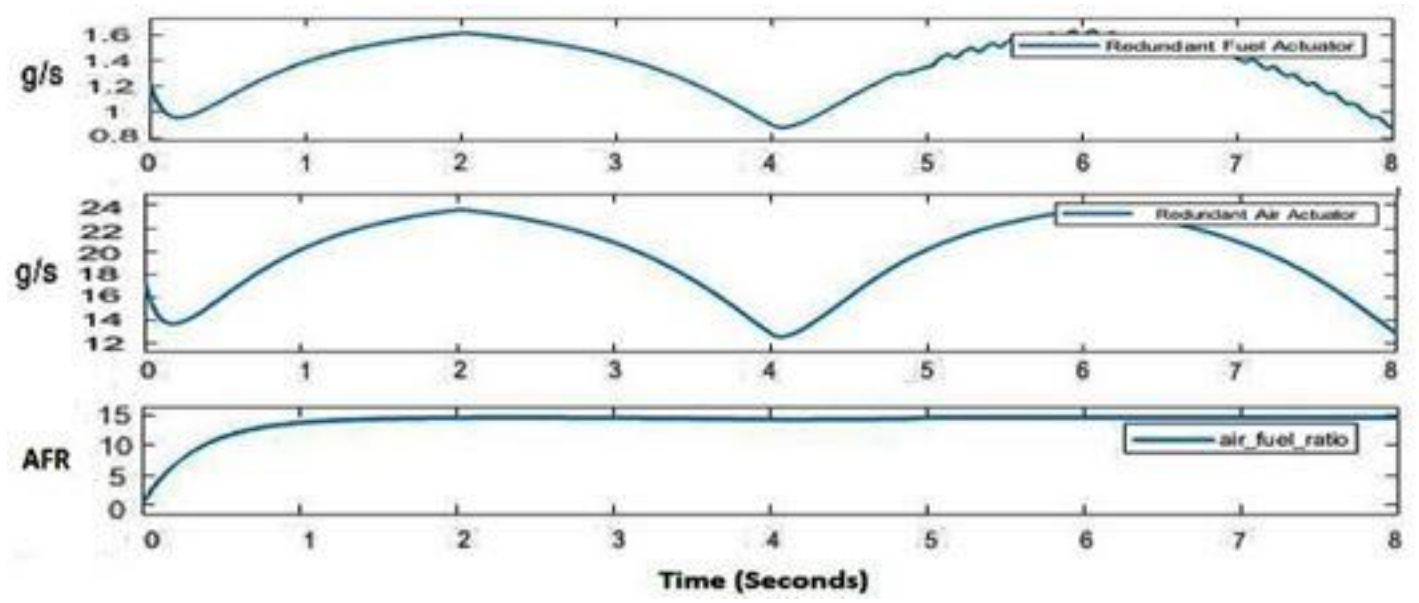

Figure9. Effects of the excess actuator assemblies
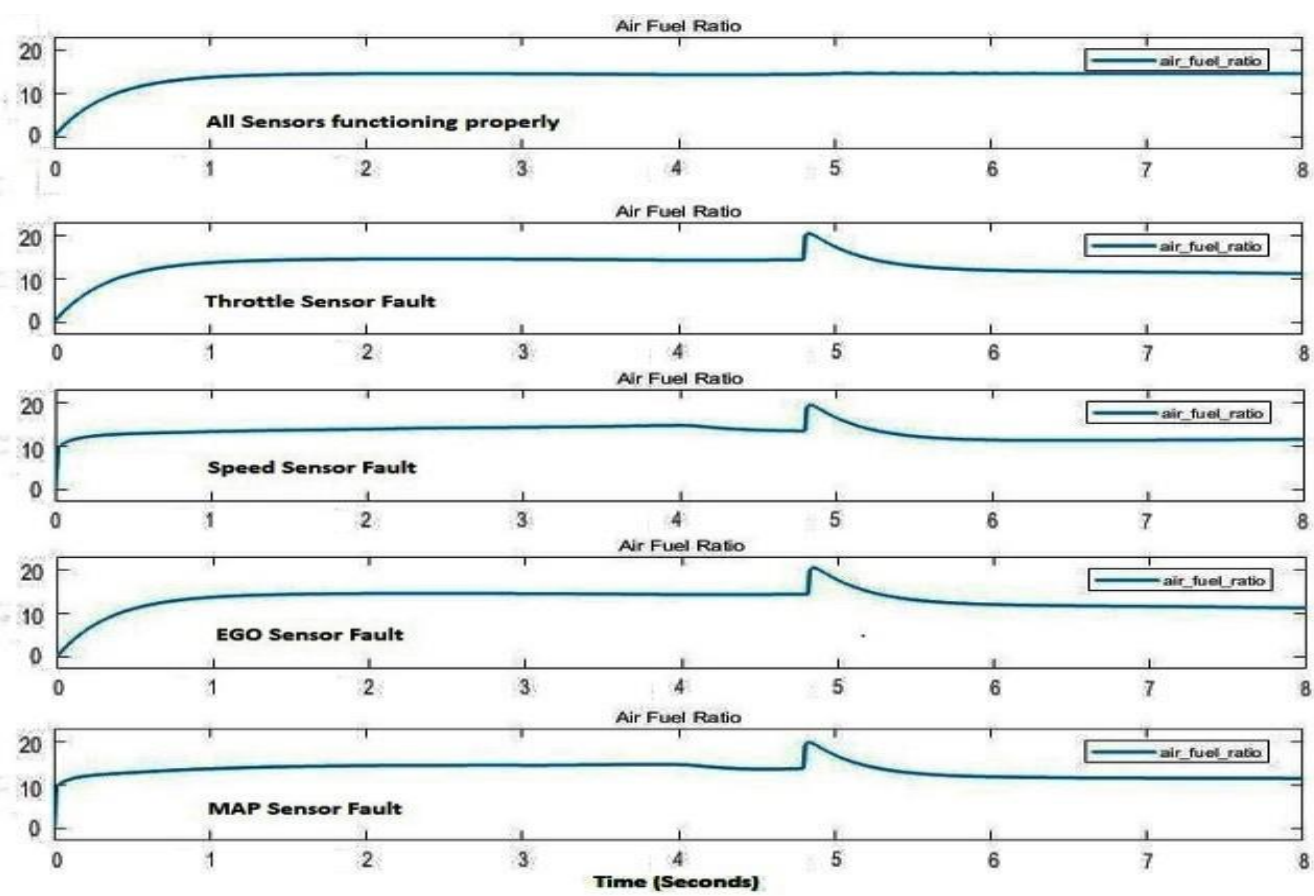

Figure10. Effect of the sensor faults on the air-fuel ratio 


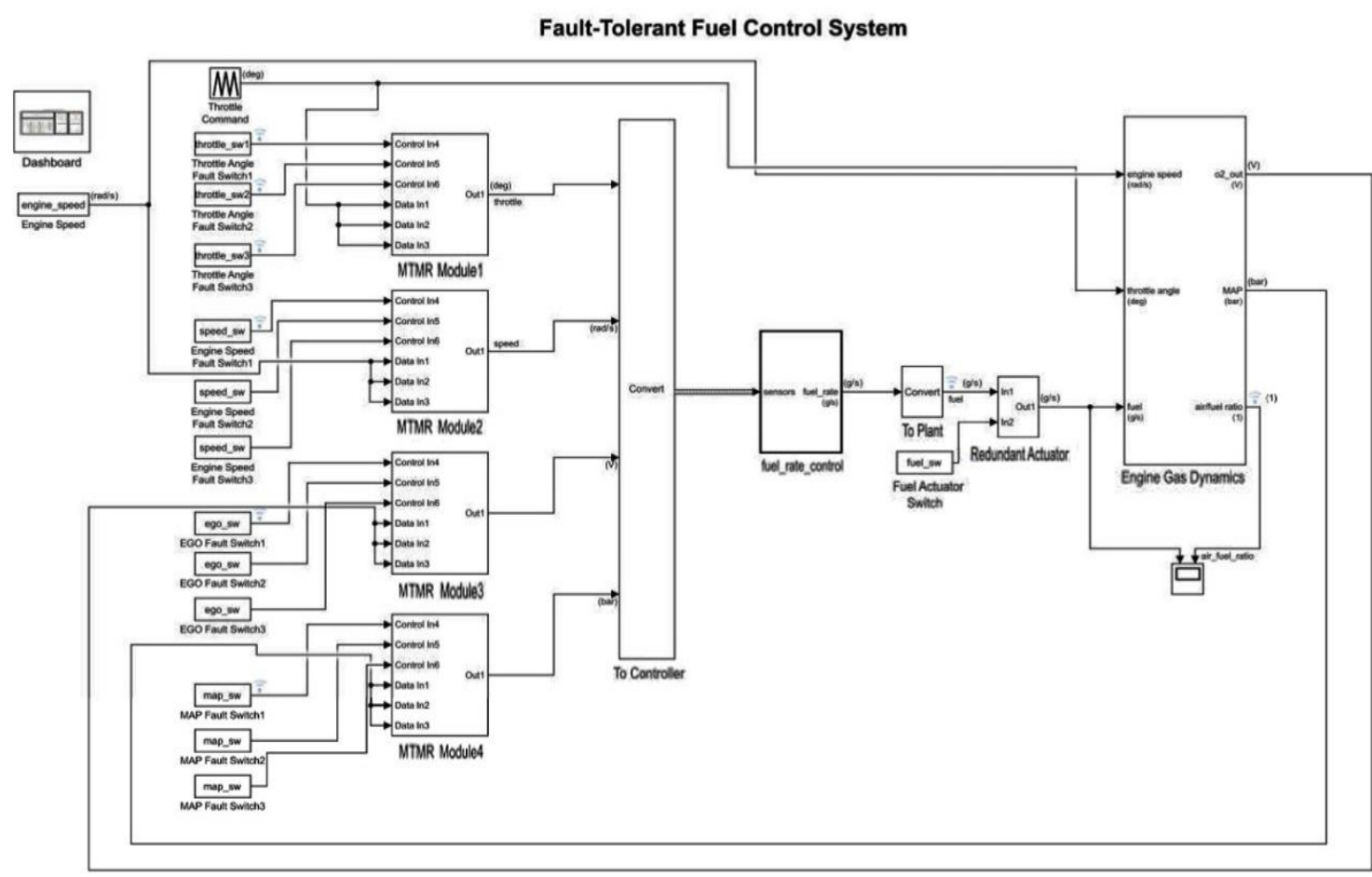

Figure11. Execution of the ATMR on sensors

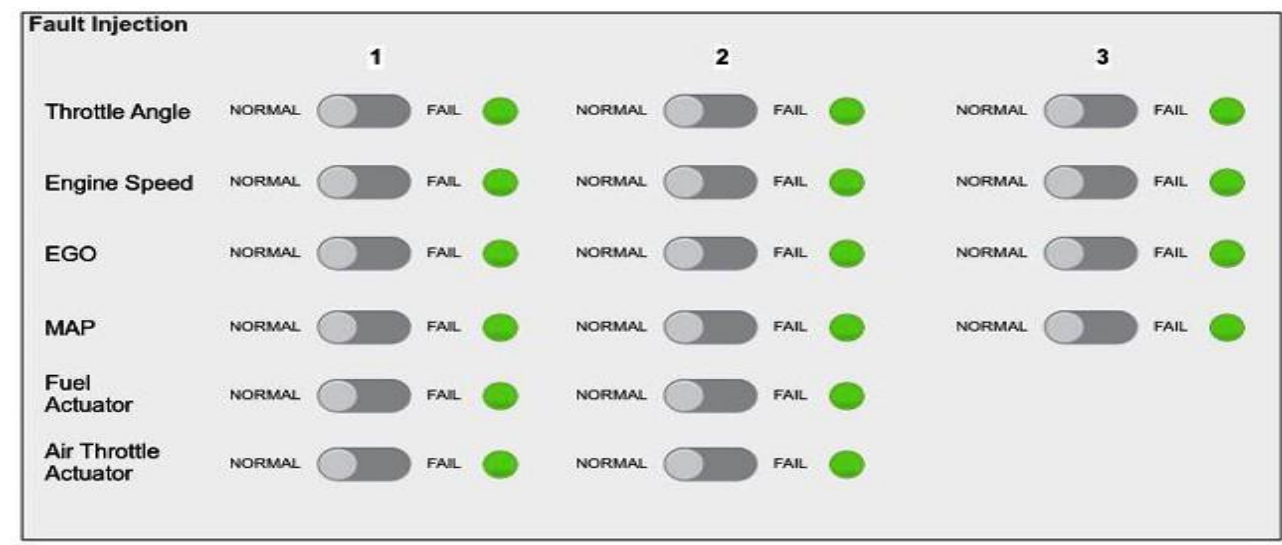

Figure12. ATMR fault simulation

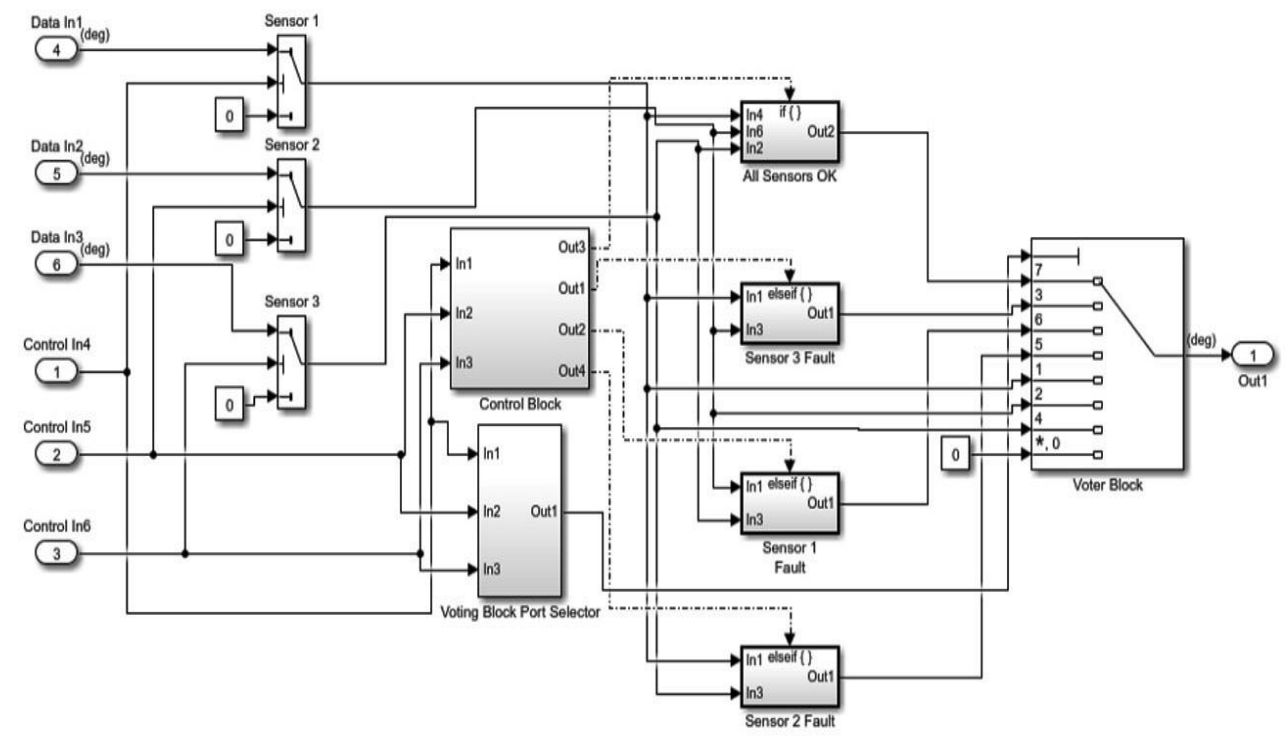

Figure13. The proposed ATMR 
Improving Fault Tolerance of Internal Combustion Gas Engine for Internal Faults Air-Fuel Ratio Control

Table1. ATMR voter port selector logic chart

\begin{tabular}{|c|c|c|c|c|}
\hline SENSOR 1 & SENSOR 2 & DETERMINATION & VOTER & TMR APPROACH ESTIMATION \\
\hline 1 & 1 & $1+2$ & 3 & STABLE \\
\hline 1 & 0 & $1+4$ & 5 & STABLE \\
\hline 0 & 1 & 2 & 2 & STABLE \\
\hline 1 & 0 & 1 & 1 & STABLE \\
\hline 0 & 0 & 0 & 0 & SYSTEM AVAILABLE \\
\hline
\end{tabular}

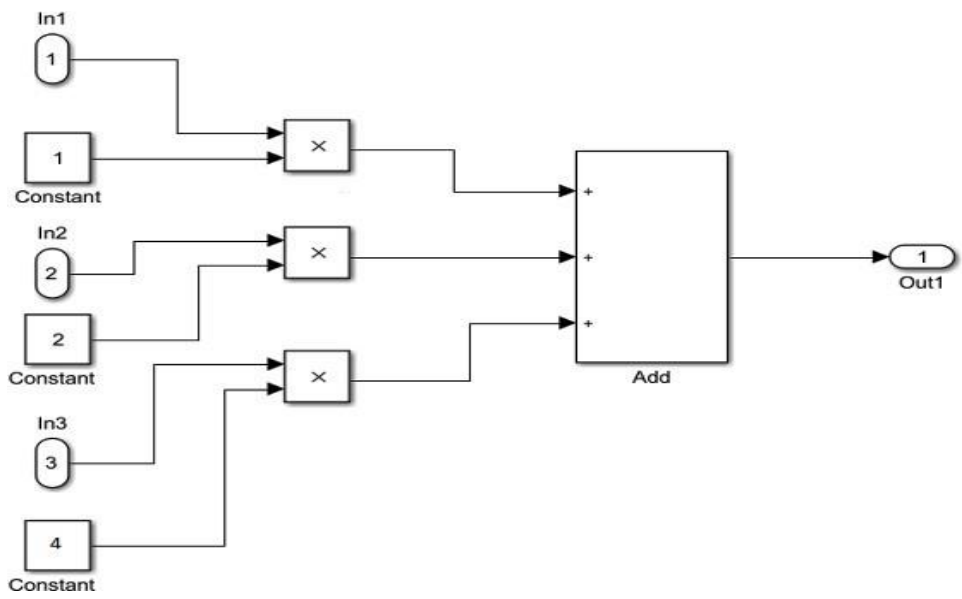

Figure14. ATMR control block
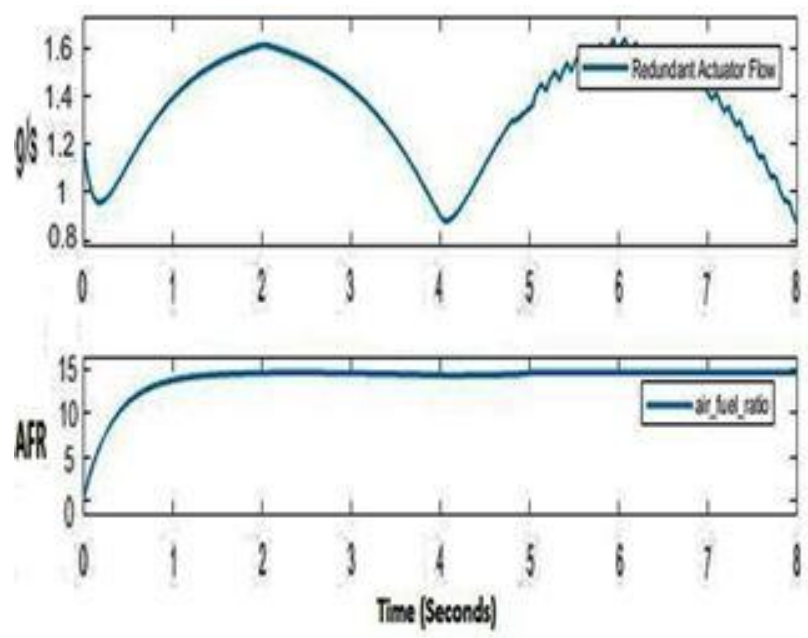

Figure15. ATMR performance for one faulty sensor
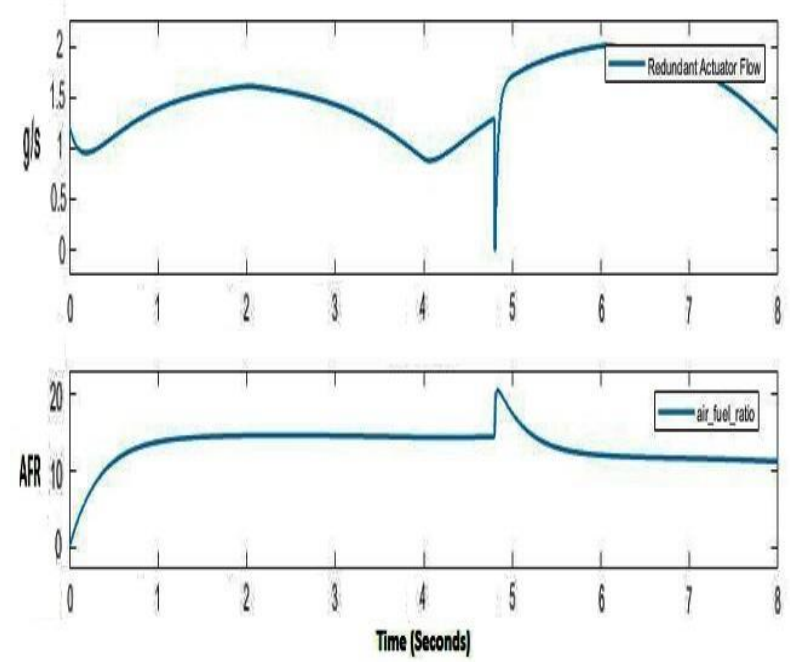

Figure16. ATMR performance for two faulty sensors in one assembly 


\section{RESUlt ANALYSIS}

The fuel actuator is included the fuel gracefully line of the motor as appeared in Fig. 3. Full ON/OFF sort actuator is considered for straightforwardness without considering halfway actuator issue. The dashboard of the control framework in MATLAB is additionally refreshed in like manner to reproduce shortcomings in the fuel and choke actuators as appeared in Fig. 4.Fuel stream, wind current and AFR in the typical running condition are appeared in Fig. 5.Now the issue is recreated in the fuel actuator. The impact of fuel actuator shortcoming on the AFR is appeared in Fig. 6. The outcomes show that the AFR proportion increments radically because of cutting off of the fuel stream by the fuel actuator's completely shut position. The impact of air choke actuator disappointment is appeared in Fig. 7.The AFR lessens to zero because of the air cut off by completely shutting of the actuator. Single actuator disappointment will be a solitary purpose of disappointment for the framework. Hence, the excess actuator get together is proposed to dodge a solitary purpose of disappointment as appeared in Fig. 8. The two actuators are introduced in corresponding with one as essential in administration and different as backup. In the event of a flaw in the essential actuator, optional comes into activity to stay away from measure interference and the defective one is secluded. The prevalent presentation of the repetitive actuator assemblies on the AFR by reproducing deficiencies is appeared in Fig. 9. The outcomes show that the AFR stays unaffected by the single actuator disappointment and the framework stays stable. In this recreation, ideal exchanging of the actuators is expected with no time delay, in any case, by and by, there is a sure time delay in the exchanging activity.

\subsection{Cost Analysis}

Total Cost and advantage examination (TCBA) is a well known strategy to decide the productivity of speculation for dynamic with respect to interest in an undertaking. TCBA helps in building up that the speculation advantages would be a lot more prominent than starting and upkeep costs caused on the framework. In this strategy, the net present worth is determined which is the contrast between current venture and all the future limited money inflows or advantages. Total cost and advantage investigation (TCBA) of adding additional actuator and sensors for the repetitive and ATMR plans is done. The market-based costs are taken in the investigation [29]-[31]. Complete expense incorporates one-time establishment cost and yearly operational costs acquired on the framework. Establishment costs incorporate expenses of extra actuators, sensors, regulator and commissioning costs. Yearly operational expenses incorporate support/fix/substitution expenses of defective segments in a year time. The breakeven time of the speculation is indicated stretch with work costs. Future advantage is taken from the cost spared because of the anticipation of shut down or creation misfortune as appeared in table. Yearly operational expenses incorporate support/fix/substitution expenses of defective segments in a year time. This examination approves the consolidation of the proposed control framework, both from the recreation study results and the monetary investigation.

Table2. Various Input data for cost and benefit analysis

\begin{tabular}{|l|l|l|l|}
\hline Component & Unit Cost & Number of Quantities & Total Cost \\
\hline Sensors & $\$ 300$ & 10 & $\$ 4000$ \\
\hline Actuators & $\$ 800$ & 2 & $\$ 2000$ \\
\hline Controller & $\$ 7000$ & 1 & $\$ 18,000$ \\
\hline Tripping Cost (malfunctioning or shutdown & $\$ 10,000$ & 6 & $\$ 30,000$ \\
\hline
\end{tabular}

Total Investment Cost: $\$ 45,000$

Total Maintenance Cost: $\$ 12,000$

\section{CONCLUSiON}

In this paper, progressed FTC equipment excess procedures were proposed and reproduced for the gas motor AFR fuel control framework. The repetitive congregations were proposed for the actuators to keep away from a solitary purpose of disappointment and a novel ATMR approach was proposed for the sensors which can proceed with activity if there should arise an occurrence of even one solid sensor. At long last, cost and advantage investigation (TCBA) was performed to legitimize the additional expense of the equipment execution for an expanded measure of sensors, actuators, and 
ATMR usage. Further work remembers the execution of the proposed method for the equipment to survey its viable execution and decide its impact on the general expansion in the size of the motor improvement. These increases will make these motors exceptionally solid for creation basic applications. Additionally, halfway blames in the actuator and keeping up AFR up to flawed conditions may likewise be considered later on work. Another future work bearing could be the usage of the FDI unit utilizing progressed investigative excess methods, for example, Fuzzy Logic (FL), Deep learning controller Technique.

\section{REFERENCES}

[1] A. Nasiri, S. K. Nguang, A. Swain, and D. Almakhles, "Passive actuator fault tolerant control for a class of MIMO nonlinear systems with uncertainties," Int. J. Control, pp. 1-12, Aug. 2017.

[2] E. Dubrova, "Hardware redundancy," in Fault-Tolerant Design. New York, NY, USA: Springer-Verlag, 2013, pp. 47-69.

[3] A. D. Pouliezos and G. S. Stavrakakis, “Analytical redundancy methods," in Real Time Fault Monitoring of Industrial Processes. Dordrecht, The Netherlands: Springer, 1994, pp. 93-178.

[4] J. Jiang, "Fault-tolerant control systems - An introductory overview,"Acta Autom. Sinica, vol. 31, no. 1, pp. 161-174, Jan. 2005.

[5] Safety Instrumented Systems. Eco Struxure Triconex Schneider Electric. [Online]. Available:https:// www.schneider-electric.com/en/work/products/industrial-automation-control/triconex-safety-systems/

[6] Instrumentation Tools. (Dec. 4, 2017). Two out of Three Logic Analogy. [Online]. Available: https://instrumentationtools.com/two-three-logic- analogy/

[7] M. D. Krstic, M. K. Stojcev, G. L. Djordjevic, and I. D. Andrejic, "A mid- value select voter," Microelectron. Reliab., vol. 45, nos. 3-4, pp. 733-738, Mar. 2005.

[8] R. Şinca and C. S. Szász, "Fault-tolerant digital systems development using triple modular redundancy," Int. Rev. Appl. Sci. Eng., vol. 8, no. 1, pp. 3-7, Jun. 2017.

[9] M. H. Rahman, S. Rafique, and M. S. Alam, "A fault tolerant voter circuit for triple modular redundant system," J. Elect. Electron. Eng., vol. 5, no. 5, pp. 156-166, Sep. 2017.

[10] S. Hudson, R. S. S. Sundar, and S. Koppu, "Fault control using triple modular redundancy (TMR)," in Progress in Computing, Analytics and Networking. Singapore: Springer, 2018, pp. 471-480.

[11] Applications | Gas Engine Controls. Accessed: Jul. 26, 2018. [Online]. Available: http://www.gasengine controls.com/applications/

[12] V. A. W. Hillier and F. W. Pittuck, Fundamentals of Motor Vehicle Tech- nology. London, U.K.: Hutchinson Educational, 1966, sec. 3.2.

[13] Air-Fuel Ratio, Lambda and Engine Performance. Accessed: Jul. 26, 2018. [Online]. Available:https://xengineer.org/automotive-engineering/internal-combustion-engines/performance/air-fuel-ratio-lambdaengine- performance/

[14] J. Lahti, "Engine management systems," in Encyclopedia of Automotive Engineering. Hoboken, NJ, USA: Wiley, 2014.

[15] Gas Engines Application and Installation Guide G3600-G3300, Caterpil- lar, Peoria, IL, USA, 1997.

[16] S. Pace and G. G. Zhu, "Air-to-fuel and dual-fuel ratio control of an internal combustion engine," SAE Int. J. Eng., vol. 2, no. 2, pp. 245-253, Nov. 2009.

[17] J. Lauber, T.-M. Guerra, and M. Dambrine, "Air-fuel ratio control in a gasoline engine," Int. J. Syst. Sci., vol. 42, no. 2, pp. 277-286, Feb. 2011.

[18] R. Anjum, I. Khan, A. Yar, and A. I. Bhatti, "Air-to-fuel ratio control of gasoline engines using smooth sliding mode algorithm," in Proc. 13th Int. Conf. Emerg. Technol. (ICET), Dec. 2017, pp. 1-6.

[19] H.-M. Wu and R. Tafreshi, "Fuzzy sliding-mode strategy for air-fuel ratio control of lean-burn spark ignition engines," Asian J. Control, vol. 20, no. 1, pp. 149-158, Jan. 2018.

[20] Y. Yuan, X. Liu, S. Ding, and B. Pan, "Fault detection and location system for diagnosis of multiple faults in aeroengines," IEEE Access, vol. 5, pp. 17671-17677, 2017.

[21] Modeling a Fault-Tolerant Fuel Control System-MATLAB \& Simulink. Accessed: Jul. 26, 2018. [Online]. Available: https://www. mathworks.com/help/simulink/examples/modeling-a-fault-tolerant-fuelcontrol-system.html

[22] R. David, P. Ngulube, and A. Dube, "A cost-benefit analysis of document management strategies used at a financial institution in Zimbabwe: A case study,” SA J. Inf. Manage., vol. 15, no. 2, p. 10, Jul. 2013. 
[23] A Student's Guide to Cost-Benefit Analysis. Accessed: Jul. 26, 2018. [Online]. Available: https://cals.arizona.edu/classes/rnr485/ch5.htm

[24] Industrial Automation Product-Price List March 2018 | Schneider Elec- tric. Accessed: Dec.15,2018.[Online].Available:https://www.schneiderelectric.co.in/en/download/document/Industrial_Au tomation_PL2018/

[25] Industrial Automation Equipments Store-Buy Online Encoders, Timers, Digital Counters. Accessed: Dec. 15, 2018. [Online]. Available: http://www.industrybuying.com/industrial-automation-2325/

[26] M. Blanke, M. Staroswiecki, and N. E. Wu, "Concepts and methods in fault-tolerant control," in Proc. Amer. Control Conf., vol. 4, Jun. 2001, pp. 2606-2620.

[27] P. M. Frank, “Trends in fault-tolerant control of engineering systems,'”IFAC Proc. Volumes, vol. 37, no. 15, pp. 377-384, Sep. 2004.

[28] Y. Wang, D. Zhou, S. J. Qin, and H. Wang, “Active fault-tolerant control for a class of nonlinear systems with sensor faults,”' Int. J. Control Autom. Syst., vol. 6, no. 3, pp. 339-350, 2008.

[29] J. Jiang and X. Yu, "Fault-tolerant control systems: A comparative study between active and passive approaches,'” Annu. Rev. Control, vol. 36, no. 1, pp. 60-72, Apr. 2012.

Citation: M.Shunmathi (2020) 'Improving Fault Tolerance of Internal Combustion Gas Engine for Internal Faults Air-Fuel Ratio Control", International Journal of Modern Studies in Mechanical Engineering, 6(2), pp. 39-50. DOI: http://dx.doi. org/10.20431/2454-9711.0602004

Copyright: (C) 2020 Authors, This is an open-access article distributed under the terms of the Creative Commons Attribution License, which permits unrestricted use, distribution, and reproduction in any medium, provided the original author and source are credited. 